\title{
Adhesion in a Vacuum Environment and its Implications for Dust Mitigation Techniques on Airless Bodies
}

Stephen Berkebile and James R. Gaier

Glenn Research Center, Cleveland, Ohio 


\section{NASA STI Program . . . in Profile}

Since its founding, NASA has been dedicated to the advancement of aeronautics and space science. The NASA Scientific and Technical Information (STI) program plays a key part in helping NASA maintain this important role.

The NASA STI Program operates under the auspices of the Agency Chief Information Officer. It collects, organizes, provides for archiving, and disseminates NASA's STI. The NASA STI program provides access to the NASA Aeronautics and Space Database and its public interface, the NASA Technical Reports Server, thus providing one of the largest collections of aeronautical and space science STI in the world. Results are published in both non-NASA channels and by NASA in the NASA STI Report Series, which includes the following report types:

- TECHNICAL PUBLICATION. Reports of completed research or a major significant phase of research that present the results of NASA programs and include extensive data or theoretical analysis. Includes compilations of significant scientific and technical data and information deemed to be of continuing reference value. NASA counterpart of peer-reviewed formal professional papers but has less stringent limitations on manuscript length and extent of graphic presentations.

- TECHNICAL MEMORANDUM. Scientific and technical findings that are preliminary or of specialized interest, e.g., quick release reports, working papers, and bibliographies that contain minimal annotation. Does not contain extensive analysis.

- CONTRACTOR REPORT. Scientific and technical findings by NASA-sponsored contractors and grantees.
- CONFERENCE PUBLICATION. Collected papers from scientific and technical conferences, symposia, seminars, or other meetings sponsored or cosponsored by NASA.

- SPECIAL PUBLICATION. Scientific, technical, or historical information from NASA programs, projects, and missions, often concerned with subjects having substantial public interest.

- TECHNICAL TRANSLATION. Englishlanguage translations of foreign scientific and technical material pertinent to NASA's mission.

Specialized services also include creating custom thesauri, building customized databases, organizing and publishing research results.

For more information about the NASA STI program, see the following:

- Access the NASA STI program home page at http://www.sti.nasa.gov

- E-mail your question to help@sti.nasa.gov

- Fax your question to the NASA STI Information Desk at 443-757-5803

- Phone the NASA STI Information Desk at 443-757-5802

- Write to: STI Information Desk NASA Center for AeroSpace Information 7115 Standard Drive Hanover, MD 21076-1320 
NASA/TM-2012-217723

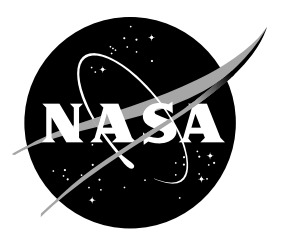

\section{Adhesion in a Vacuum Environment and its Implications for Dust Mitigation Techniques on Airless Bodies}

Stephen Berkebile and James R. Gaier

Glenn Research Center, Cleveland, Ohio

Prepared for the

42nd International Conference on Environmental Systems

sponsored by the American Institute for Aeronautics and Astronautics

San Diego, California, July 15-19, 2012

National Aeronautics and

Space Administration

Glenn Research Center

Cleveland, Ohio 44135 


\section{Acknowledgments}

The authors thank Ken Street for discussion and coordination of synthetic noritic glass preparation, Mike Weinstein of Zybek Advanced Products for supplying the synthetic noritic glass, Dave Hull for glass sample cutting, Joy Buehler for glass polishing, Scott Panko, Frank Lam and Rick Mondry for support in the laboratory, and Nicholas Garafolo and Henry De Groh for providing the S0383-70 sample. Financial support was provided by NASA ETDP Thermal Control and Dust Mitigation Projects through the NASA Postdoctoral Program (administered by Oak Ridge Associated Universities).

Trade names and trademarks are used in this report for identification only. Their usage does not constitute an official endorsement, either expressed or implied, by the National Aeronautics and Space Administration.

Level of Review: This material has been technically reviewed by technical management.

Available from

NASA Center for Aerospace Information 7115 Standard Drive

Hanover, MD 21076-1320
National Technical Information Service 5301 Shawnee Road Alexandria, VA 22312 


\title{
Adhesion in a Vacuum Environment and its Implications for Dust Mitigation Techniques on Airless Bodies
}

\author{
Stephen Berkebile ${ }^{1}$ and James R. Gaier \\ National Aeronautics and Space Administration \\ Glenn Research Center \\ Cleveland, Ohio 44135
}

\begin{abstract}
During the Apollo missions, the adhesion of dust to critical spacecraft systems was a greater problem than anticipated and resulted in functional degradation of thermal control surfaces, spacesuit seals, and other spacecraft components. Notably, Earth-based simulation efforts did not predict the magnitude and effects of dust adhesion in the lunar environment. Forty years later, we understand that the ultrahigh vacuum (UHV) environment, coupled with micrometeorite impacts and constant ion and photon bombardment from the sun result in atomically clean and high surface energy dust particles and spacecraft surfaces. However, both the dominant mechanism of adhesion in airless environments and the conditions for high fidelity simulation tests have still to be determined. The experiments presented in here aim to aid in the development of dust mitigation techniques for airless bodies (e.g., lunar surface, asteroids, moons of outer planets). The approach taken consists of (a) quantifying the adhesion between common polymer and metallic spacecraft materials and a synthetic noritic volcanic glass, as a function of surface cleanliness and of triboelectric charge transfer in a UHV environment, and (b) determining parameters for high fidelity tests through investigation of adhesion dependence on vacuum environment and sample treatment. Adhesion force has been measured between pins of spacecraft materials and a plate of synthetic volcanic glass by determining the pull-off force with a torsion balance. Although no significant adhesion is generally observed directly as a result of high surface energies, the adhesion due to induced electrostatic charge is observed to increase with spacecraft material cleanliness, in some cases by over a factor of 10. Furthermore, electrostatically-induced adhesion is found to decrease rapidly above pressures of $10^{-6}$ torr. It is concluded that high-fidelity tests should be conducted in high to ultrahigh vacuum and include an ionized surface cleaning process.
\end{abstract}

\section{Nomenclature}

AZ-93 inorganic white thermal control paint

$b_{1}, b_{0} \quad$ fitting parameters

$F_{\text {adh }} \quad$ force of adhesion

FEP fluorinated ethylene propylene

PC polycarbonate

PTFE polytetrafluoroethylene

RMS root mean square

$U_{\text {strike }} \quad$ energy of strike

UHV ultrahigh vacuum

\footnotetext{
${ }^{1}$ NASA Glenn Research Center, NASA Postdoctoral Fellow, Oak Ridge Associated Universities.
} 


\section{Introduction}

In the Review of United States Human Space Flight Plans Committee report of 2009, two of three paths considered to the final goal of Mars include travel first to the Moon or to "near-Earth objects ... and the scientifically interesting moons of Mars, ...." (Ref. 1). All of these bodies are airless bodies, with a vacuum environment exceeding that attainable in chambers on Earth, and are under constant bombardment by space plasmas, high energy particles, high energy electromagnetic radiation, and micrometeorites (Refs. 2 to 4 ). Additionally, the Moon, the moons of Mars and many asteroids are covered by a layer of regolith which contains a significant amount of fine to ultrafine particulate matter. Our experience with the Apollo missions showed that when exposed to dust in vacuum, the performance of thermal control surfaces is seriously degraded (Ref. 5), photovoltaic efficiency is decreased (Refs. 6 and 7), mechanical systems are compromised through abrasion (Ref. 5) and optical elements of cameras and telescopes are scratched or occluded (Ref. 8). As a result, these and other systems may fail when operating in a dusty vacuum environment if effective mitigation strategies are not developed and implemented.

Under the conditions of ultrahigh vacuum (UHV, $<10^{-9}$ torr) found at the surfaces of airless bodies, dust behaves very differently than in our atmosphere (Refs. 2 and 5). Dust adhesion properties are thought to be enhanced by two classes of mechanisms, increased surface energy and electrostatic attraction. Firstly, particles of dust are made more reactive through "space weathering" processes of ion bombardment and micrometeorite impacts which create smaller dust particles and freshly fractured surfaces. In UHV environments, the atomic cleanliness of freshly fractured surfaces is maintained and the population of chemically reactive surface species remains significant due to the scarcity of molecules in the gas phase colliding with the surface of the dust. The particle bombardment of the dust (and, with exposure time, the spacecraft materials) in the UHV environment results in the absence of a thin film of hydrocarbons and water that exists on surfaces in our atmosphere. As a result, the adhesion of dust is enhanced up to two orders of magnitude, primarily due to Van der Waals interactions (Ref. 9). The second mechanism which can enhance dust adhesion arises from electrostatic forces. For example, most lunar particles are composed of nonconductive minerals and glasses and will build up a equilibrium static charge under constant ion and photon bombardment (Refs. 10 and 11). Such effects lead to positive charge on the surface of the moon facing the Sun (photoelectric effect) and negative charge on the dark side (electrons from the solar wind) (Ref. 10).

As a result of space weathering under UHV conditions and the mechanisms listed above which lead to an increased adhesion, dust mitigation strategies which work under atmospheric conditions cannot be assumed to work on the surfaces of airless bodies. As the Apollo missions have shown, even tests in low to high vacuum environments can lead to misleading results which do not accurately simulate the lunar environment (Ref. 2).

In this study we address the issues of adhesion on airless bodies by using well-defined conditions which attempt to simulate a lunar environment combined with simple model systems of lunar and spacecraft materials to determine which mechanism, electrostatic or high surface energies, causes the greatest adhesion. To this end, the adhesion between pins of spacecraft materials and a plate of lunar simulant glassy material has been investigated in a UHV environment. The materials can be tested with control of their surface atomic cleanliness, as well as their electrostatic charge. This study includes measurements of adhesion due to both Van der Waals forces and electrostatic charging induced by triboelectric charging.

Until recently, it was unclear whether surface energy or electrostatic forces dominate for different particle sizes and for different types of dust. This investigation demonstrates that the electrostatic charge is the dominant mechanism of adhesion that can be expected in an airless body environment, and that particular attention must be given to issues of triboelectric charging. The triboelectric charge transfer is found to be sensitive to surface atomic cleanliness of the samples, and electrostatically induced adhesion is affected by background pressures exceeding $10^{-6}$ torr. Therefore, mitigation techniques should be tailored to deal with electrostatic forces. Furthermore, high fidelity tests and validation of dust mitigation techniques should include a step to remove surface contamination and be conducted in high to ultrahigh vacuum. 


\section{Experimental}

This work aims to understand the adhesion forces between lunar dust and thermal control surfaces in the lunar environment, but the actual experiment necessarily makes several compromises. A torsion balance was used to measure the pull-off force (Ref. 12), so only macroscopic samples could be used. A plate of synthetic norite volcanic glass with a lunar-like composition (Zybek Advanced Products, Boulder, CO) was used in place of the lunar dust. As determined by Auger electron spectroscopy, the chemical composition of the synthetic noritic glass surface is approximately 48 percent $\mathrm{O}, 18$ percent $\mathrm{Si}, 16$ percent $\mathrm{Ca}$, 12 percent $\mathrm{Al}$, and 6 percent $\mathrm{Mg}$. The synthetic glass was produced by melting noritic materials from the Stillwater mine and quench cooling them. This material is also used as a source for the glass content in NU-LHT lunar regolith simulant. Lunar vacuum was simulated in an ultrahigh vacuum (UHV) chamber which was pumped to a vacuum of $10^{-10}$ torr or better, but still two orders of magnitude higher than lunar vacuum. Ion bombardment by the solar wind was simulated by sputtering the surfaces with $\mathrm{Ar}^{+}$ions.

The spacecraft materials were in the form of polished $3.2 \mathrm{~mm}$ diameter pins with hemispherical ends (radius $=1.6 \mathrm{~mm})$. Most pins were polished mechanically with diamond paper down to $0.1 \mu \mathrm{m}$.

Polycarbonate (PC) was polished with $\mathrm{AlO}_{\mathrm{x}}$ paper and then chemically polished with a methylene chloride vapor. Mylar and Tedlar were used in the form of sheets spanned over an aluminum pin of the above curvature with no further treatment. Soda-lime glass was melted to the desired curvature. Silicone rubber S0383-70 (Parker Hannifin) was obtained in the form of an o-ring seal with tube radius of $1.3 \mathrm{~mm}$ and ring diameter $9 \mathrm{~mm}$. AZ-93 paint (zinc orthotitanate in a potassium silicate binder) was applied to an aluminum pin (AZ Technologies, Huntsville, AL) and used as-received. All samples were rinsed in pure ethanol prior to placement in the UHV chamber. A list of the materials used can be found in Table 1 next to the root-mean-square surface roughness as measured by a Veeco/Wyko NT 1000 optical profilometer and the Young's moduli of the materials.

The experimental details have been described fully previously (Ref. 13), but the concept is straightforward. The hemispherical end of the pin being measured is driven towards the glass plate with a speed of $9.3 \mu \mathrm{m} / \mathrm{s}$. It continues to be driven until the plate is pushed back which twists the torsion wire. After being displaced to a load of 0.1 to $0.5 \mathrm{mN}$, as measured by a differential variable reluctance transducer (DVRT) which measures the position of a balance arm on the opposite side of the plate, the drive motor is halted, and the pin and plate remain in contact for a specified, but variable, period of time, usually 15 to $30 \mathrm{sec}$. Then the pin is withdrawn from the plate at the same speed. After passing the torsion balance equilibrium point, the wire tends to pull the plate and pin apart. Separation occurs when the spring force equals the adhesion force. Examples of the raw data can be found in Reference 13.

TABLE 1.-APPROXIMATE RMS ROUGHNESSES OF PLATE AND

PIN SURFACES BEFORE ADHESION MEASUREMENTS IN THE

UHV CHAMBER AND YOUNG'S MODULUS OF MATERIALS (FROM ENGINEERINGTOOLBOX.COM)

\begin{tabular}{|l|c|c|}
\hline \multicolumn{1}{|c|}{ Material } & $\begin{array}{c}\text { RMS roughness, } \\
\mathrm{nm}\end{array}$ & $\begin{array}{c}\text { Young's Modulus, } \\
\mathrm{GPa}\end{array}$ \\
\hline Noritic glass plate & $<30$ & 50 to 90 \\
\hline PC & 90 & 2.6 \\
\hline PTFE & 130 & 0.5 \\
\hline FEP & 250 & 0.5 \\
\hline Ti-6-4 & 300 & 114 \\
\hline Al-6061 & 170 & 69 \\
\hline Soda-lime glass & -------- & 50 to 90 \\
\hline Mylar (boPET) & 110 & 2 to 2.7 \\
\hline Tedlar (PVF) & 150 & --------- \\
\hline Silicone rubber S0383-70 & 620 & 0.001 to 0.005 \\
\hline AZ-93 & -------- & -------- \\
\hline
\end{tabular}


A variation on the procedure was used to apply an electrostatic charge. The pin was placed $50 \mu \mathrm{m}$ from the plate. It was then quickly brought into contact with the plate in a striking motion and retracted. Under many conditions this resulted in the deposition of charge on the pin, the plate, or both. This motion resulted in one large and several smaller bounces between the pin and plate. The strength of the strike was registered by the greatest displacement of the balance due to the strike. This displacement was then converted into potential energy from which the kinetic energy of the strike was assumed. The magnitude of charge deposition was inferred from the measured electrostatic adhesion force. The adhesion force was measured three to ten times after a strike at the strike position and was generally found to have little variation for any particular strike. The standard deviation of the adhesion measurements for a single strike is given as error bars in the figures.

Two types of adhesion forces could be observed, electrostatic and non-electrostatic (Van der Waals, chemical), which were distinguished by their functional dependence on separation and therefore their range. Measurements of the adhesion force were made under different loads, typically in the range of 0.1 to $0.5 \mathrm{mN}$. The duration of the loads was $30 \mathrm{sec}$ for the measurements of non-electrostatic adhesion whereas the loads were typically maintained $15 \mathrm{sec}$ for cases of electrostatic adhesion. No dependence on the load duration or magnitude was seen for electrostatic adhesion. The adhesion force values given throughout this report are generally the average of three or more contacts with the standard deviation shown as error bars.

The surfaces of the materials were cleaned by bombardment with $8.5 \mu \mathrm{A} / \mathrm{cm}^{2}$ beam of $\mathrm{Ar}^{+}$ions accelerated to $2 \mathrm{keV}$ from an ion gun (sputter cleaning). This process removed atmospheric contamination due to water and organic compounds from mineral surfaces and created a number of broken bonds, both of which leave the surface in a state similar to that which dust particles have in an airless body environment. Metals were sputtered until no improvement in the $\mathrm{C}$ and $\mathrm{O}$ surface contamination could be discerned using an Auger electron spectrometer before each measurement. Plastic materials were sputtered for $30 \mathrm{sec}$ to $5 \mathrm{~min}$ each day before measurements. No dependence on sputter duration was seen after the initial sputter cycle. The synthetic volcanic glass was cleaned through ion bombardment prior to all measurements, unless explicitly stated.

\section{Adhesion in UHV Environment}

\section{Non-Electrostatic Adhesion}

The adhesion force due to Van der Waals and other short range interactions, such as chemical bonding, was below the apparatus detection limits $(-5 \mu \mathrm{N})$ for most of the glass and pin sample pairs. (Since adhesion is an attractive force it is given a negative sign. Applied loads are positive in sign.) Forces as high as $10 \mathrm{mN}$ were applied to press the pin and plate together, and were held as long as $10 \mathrm{~min}$. The results were the same whether the volcanic glass was tested "dirty" or had been sputter cleaned, and whether the pin was dirty or cleaned.

There were three exceptions which displayed some form of non-electrostatic adhesion: the PTFE and 6061 aluminum pins and the S0383-70 o-ring. Interestingly, these three materials are different in their chemical and material properties, as well as the typical applications for which they are utilized. PTFE is often used when a non-stick surface is desired, while the silicone rubber S0383-70 is a candidate material for docking seals, an application in which gas-impermeable contact is sought. Al-6061 is a structural material which is not generally considered for its adhesive properties (or lack thereof).

In the case of PTFE, the adhesion force ranged from -0.02 to $-0.10 \mathrm{mN}$, and depended on the magnitude of the applied force in a roughly linear fashion for any particular contact position (Fig. 1). However, the adhesion varied widely between contact locations, even for similarly treated samples. Leaving the pin attached to the glass at a load of $1.9 \mathrm{mN}$ for a period of $2 \mathrm{hr}$ resulted in an increase in the adhesion force by a factor of 5 to 10 over 30-second-long loads. Sputter cleaning the glass increased the adhesion force by about a factor of 4 . Cleaning both the glass and the PTFE pin increased the adhesion an additional factor of 2 for some positions. 

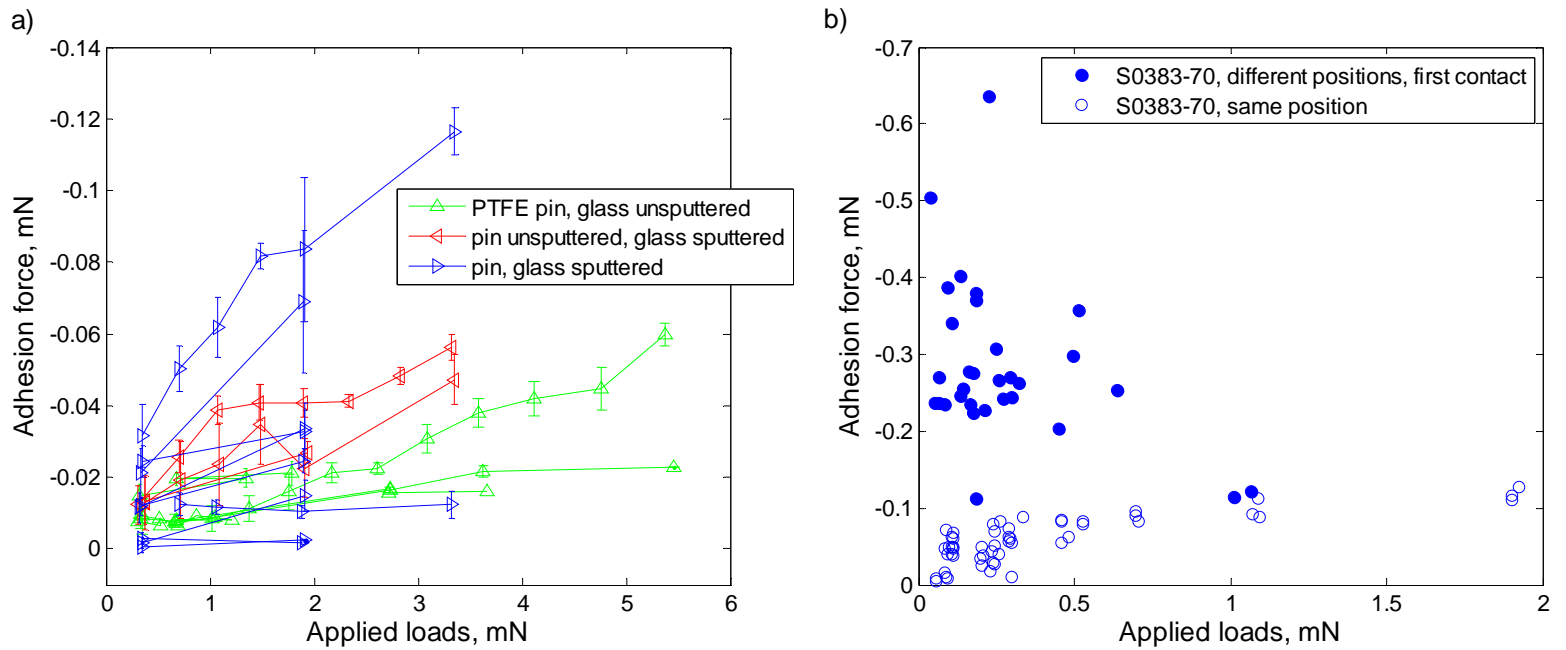

Figure 1.-Adhesion force due to Van der Waals and chemical interactions as a function of load for a) PTFE pin and b) S0383-70 silicone rubber o-ring on synthetic volcanic glass. Measurements of different loads at any particular contact position are connected by lines in a).

S0383-70 displayed non-electrostatic adhesion on sputter-cleaned glass when the o-ring was not treated after insertion in the vacuum system. The adhesion behavior was fairly erratic and varied greatly depending on the particular contact location selected, even though these locations were all of the same geometry. The adhesion for first contact at any particular location ranged from -0.1 to $-0.65 \mathrm{mN}$, but was not dependent on the applied load, as can be seen in Figure 1. Further contacts at the same position always resulted in a greatly reduced adhesion force which would reduce within two to four contacts to a steady value between 20 percent of the original value to non-measureable. If adhesion was measureable for further contacts, these were found to be load-dependent, as shown for a particular location in Figure 1. When the o-ring was sputter cleaned, the non-electrostatic adhesion was no longer measureable, perhaps due to chemical modification of the surface through the breaking of bonds. Note that atomic oxygen treatment of such samples leads to a glassy surface which decreases total adhesion under large loads (Ref. 14).

The 6061 aluminum pins adhesion ranged from -0.01 to $-0.08 \mathrm{mN}$ and exhibited behavior that was difficult to interpret. Contrary to expectations, the adhesion force decreased at higher applied forces. Although there was a wide range of adhesion values, all values greater than $-0.02 \mathrm{mN}$ occurred when the applied load was less than $0.4 \mathrm{mN}$.

The mechanisms of non-electrostatic adhesion for these three samples can only be speculated on, but some evidence of the mechanisms is available from the conducted measurements. The S0383-70 displayed the largest adhesion, which then reduced with further contacts, suggesting that the position of contact was changing. Indeed, some evidence of material transfer was observed, in that the volcanic glass plate sometimes showed a tendency to charge during Auger electron spectroscopy measurements after numerous contacts were made. Although no significant amount of carbon was seen to transfer to the surface (and Si and $\mathrm{O}$ were already present in large amounts in the glass), a change in the secondary electron emission characteristics clearly occurred. It is possible that a chemical interaction is taking place at the silicone/silicate interface which is stronger than the cohesive force of the silicone rubber, with further Van der Waals forces present after chemical modification is complete. No transfer of $\mathrm{Al}$ or $\mathrm{Mg}$ was seen from the glass plate to the o-ring. 
The smaller adhesion of the PTFE to the glass is unlikely to be chemical in nature, as PTFE is one of the most chemically inert substances known. PTFE is subject to creep of the polymer chains due to the lack of cross-linking. The load- and time-dependent adhesion values observed suggest that physical deformation of the PTFE tip is occurring. We propose that, even though PTFE is known to have low Van der Waals adhesion values, by conforming to the glass surface, the roughness of the PTFE is overcome and a large enough contact area is created for Van der Waals adhesion to become significant. Due to the smoothness of the glass, the mechanism of adhesion is not likely to be from mechanical interlocking.

\section{Triboelectric Charging}

Electrostatic adhesion was induced through triboelectric charge transfer between the spacecraft materials and the glass plate. Figure 2 shows the electrostatic adhesion force for individual strikes each with a particular strike energy, as calculated from the balance deflection due to the strike. As is shown in Figure 2, this triboelectric charge transfer increased with strike energy over the range of the strike kinetic energy, 1 to $15 \mu \mathrm{J}$, which indicates that electrostatic adhesion forces increased with the amount of charge transferred upon striking the pin to the plate. Comparisons of adhesion data are more clearly illustrated in Table 2, which shows the average adhesion per unit strike energy. This value was determined by dividing the adhesion measured in a particular experiment by the kinetic strike energy applied. Thus, materials with higher values converted more of the kinetic energy into charge separation, which resulted in greater electrostatic adhesion.
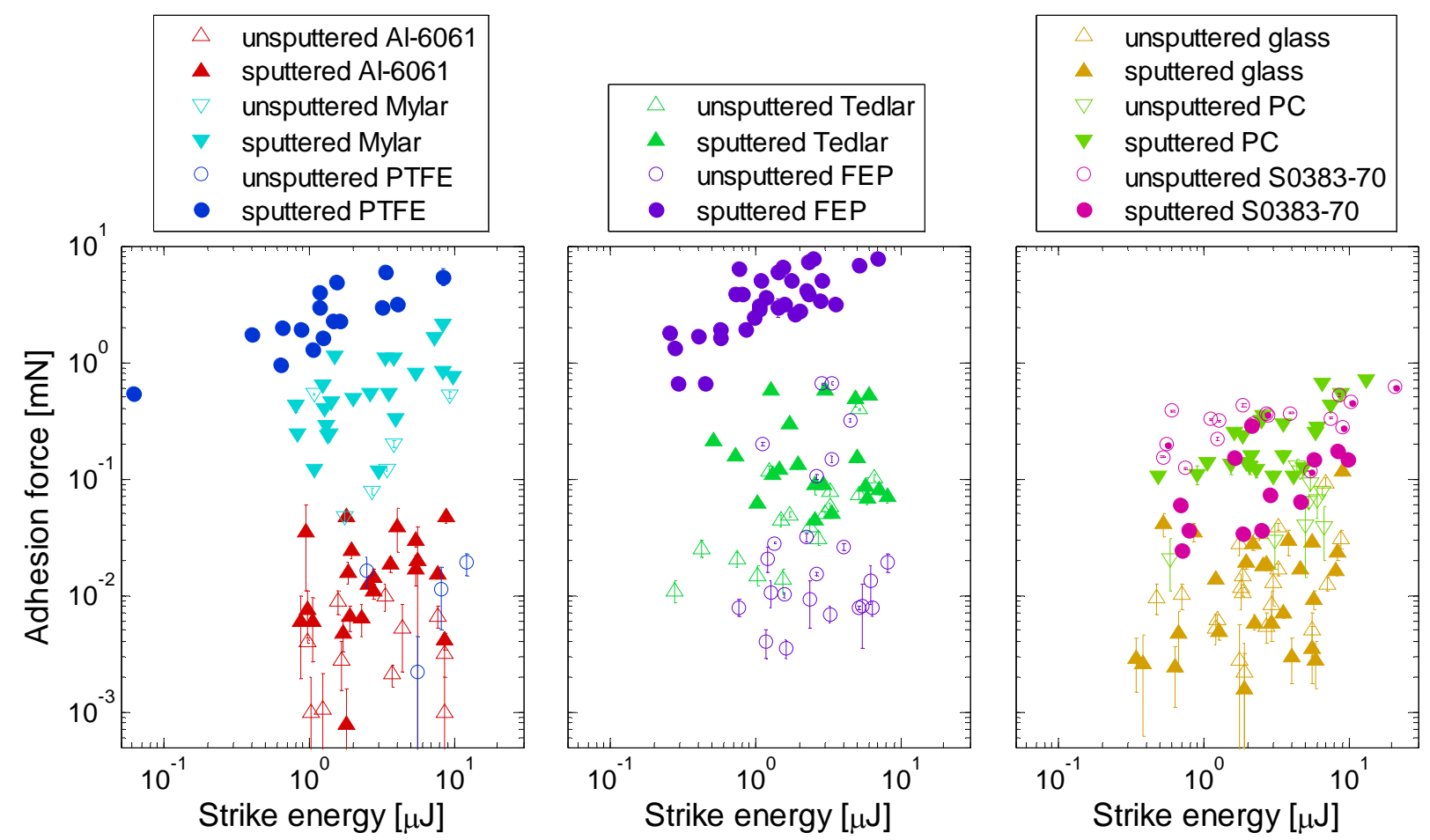

Figure 2.-Measured electrostatic adhesion force as a function of the kinetic energy of striking the pin against synthetic volcanic glass. Note that all logarithmic axes are equal for the three graphs. 
TABLE 2.-MEASURED AVERAGE ELECTROSTATIC ADHESION FORCE PER KINETIC ENERGY OF THE STRIKING OF THE PIN AGAINST SYNTHETIC VOLCANIC GLASS

\begin{tabular}{|l|c|c|c|}
\hline \multirow{2}{*}{ Material } & \multirow{2}{*}{$\begin{array}{c}\text { Triboelectric } \\
\text { affinity, } \\
\text { nC/J }\end{array}$} & \multicolumn{2}{c|}{$\begin{array}{c}\text { Average adhesion force per strike energy, } \\
\text { N/J }\end{array}$} \\
\cline { 2 - 4 } & --- & as is & sputter cleaned \\
\hline Ti-6-4 & --- & $\ddagger$ & $\ddagger$ \\
\hline Al 6061 & +25 & -1.8 & -7.4 \\
\hline Glass (soda lime) & --- & -7.2 & -10.1 \\
\hline AZ-93 & -5 & $\ddagger$ & + \\
\hline Polycarbonate & --- & -16.5 & -84.4 \\
\hline Tedlar & -40 & -30.9 & -240 \\
\hline Mylar & -72 & -116 & -43.9 \\
\hline Silicone rubber S0383-70 & -190 & -173 & -2410 \\
\hline PTFE & -190 & -0.9 & -3020 \\
\hline FEP & -37.6 & \\
\hline
\end{tabular}

Indicates non-detectable adhesion below $-0.005 \mathrm{mN}$, i.e. about $-0.3 \mathrm{~N} / \mathrm{J}$.

* from Triboelectric Table (Bill Lee, Alpha Lab Inc., 2009).

A clear difference is seen for most materials between the low to non-measureable charge transfer of the state "as inserted" into the UHV chamber and the high charge transfer of the "sputtered" samples. Sputter cleaning was conducted for $15 \mathrm{sec}$ to $2 \mathrm{~min}$ for any particular polymer, and until a clean sample was obtained for the metals. As noted elsewhere (Ref. 15), such sputter treatment corresponds to an exposure of a few hours on the lunar surface. The exception to this rule was the S0383-70, which had the largest average charge transfer in the unsputtered state. Once sputtered, the triboelectrically-induced adhesion values were decreased, reminiscent of the decrease seen in the adhesion values after sputtering for non-electrostatic adhesion in the previous section.

Table 2 lists the materials in order of their triboelectric affinity. A positive value tends to give up electrons and become positively charged, and a negative value tends to gain electrons and take on a negative charge. The synthetic volcanic glass probably has a triboelectric affinity near that of soda lime glass. Electrons are so mobile in metals that they do not retain charge. Note that the adhesion forces, particularly for the cleaned materials, are well correlated to the triboelectric affinity.

The strike energy values of 1 to $15 \mu \mathrm{J}$ correspond roughly to the kinetic energy of spherical silica particles 0.4 to $1 \mathrm{~mm}$ in diameter when dropped onto a surface from the height of one meter in Earth's gravity. If such a particle strikes PTFE or FEP, the electrostatic adhesion induced will be 1000 times the force of gravity acting on that particle (or 10 to 100 times the force of gravity when striking other polymer materials). The situation will be similar on the lunar surface, despite having only $1 / 6$ of the Earth's gravity. Since the potential energy of a particle depends linearly both on its height above a surface and on the gravitational force, the electrostatic adhesion after a fall of one meter on the Moon will be 1000/6 = 167 times that on Earth (which is still 1000 times the force of gravity on the Moon). Particles lofted by human activity through a trajectory with horizontal motion will have additional translational energy.

In order to see how the induced electrostatic adhesion might scale to smaller values, both linear and exponential fits were attempted. The results were less than satisfactory. An exponential fit $F_{\text {adh }}=b_{0} U_{\text {strike }}^{b_{1}}$, with exponents $b_{1}$ less than zero, seemed to fit best for the largest values of adhesion with sputtered FEP and PTFE, but no fit could be found which provided confidence. While there is little variation in the adhesion measured as the result of any particular strike (several measurements after a strike result in the small standard deviation shown by the error bars), there is a large scatter between values measured as the result of different strikes. The large scatter in the data likely arises from the method of striking, which, while providing an exact maximum strike energy, includes several smaller contacts for each data point shown. To resolve the question of scaling to smaller particle sizes, further measurements will need to be conducted. 


\section{Effect of Vacuum on Charged Adhesion}

Surface cleanliness has been shown to be an important factor for the triboelectric charge transfer. After the initial $\mathrm{Ar}^{+}$ion sputter cleaning of the surfaces used in this study, the cleanliness will depend on the quality of the vacuum environment. Likewise, once the charge transfer has taken place, the persistence of the charge on the surface and, hence, the electrostatic adhesion depends on the quality of the vacuum environment. Mechanisms of discharging an electrically charged surface are numerous and include collisions with gas, conduction, electron/ion bombardment (directly through charge neutralization or indirectly through secondary emission), and photoelectric emission. Conduction can be aided by a layer of water on the surface in a humid environment or by the inner photoelectric effect creating free charge carriers in an otherwise largely insulating material. On an airless body, the methods of discharge will be limited to solar wind plasma currents, photoelectric emission, and conduction, the latter of which is negligible for the polymers considered here and largely irrelevant for the lunar regolith. In fact, Farrell et al. (Ref. 16) worry about the lack of the former two mechanisms for discharge of triboelectrically-induced charge in the craters of the lunar polar regions.

In the absence of background gases and electron or ion currents, strong electrostatic adhesion was observed here to persist for a period of at least several days with no significant degradation in a vacuum of $10^{-10}$ torr. For more details, see Reference 13 where only a small drop in the strength of the electrostatic adhesion is seen over several hours. To test the robustness of the electrostatic adhesion with variation of background pressure, Argon gas and air were leaked into the UHV chamber while measuring the adhesion force of an FEP pin to the glass after striking. Once the charged pin has been exposed to Argon or air at pressures around $10^{-6}$ torr, a drastic drop in the adhesion force occurs (Fig. 3(a) and (b), respectively).

The charge on the pin and on the glass plate could be observed by scanning electron microscopy as a large distortion in the image. It was observed that full discharge of triboelectrically induced charge areas could be achieved with $100 \mathrm{~s}$ of $\mu \mathrm{A} / \mathrm{cm}^{2}$ in 1 to 2 sec.

a)

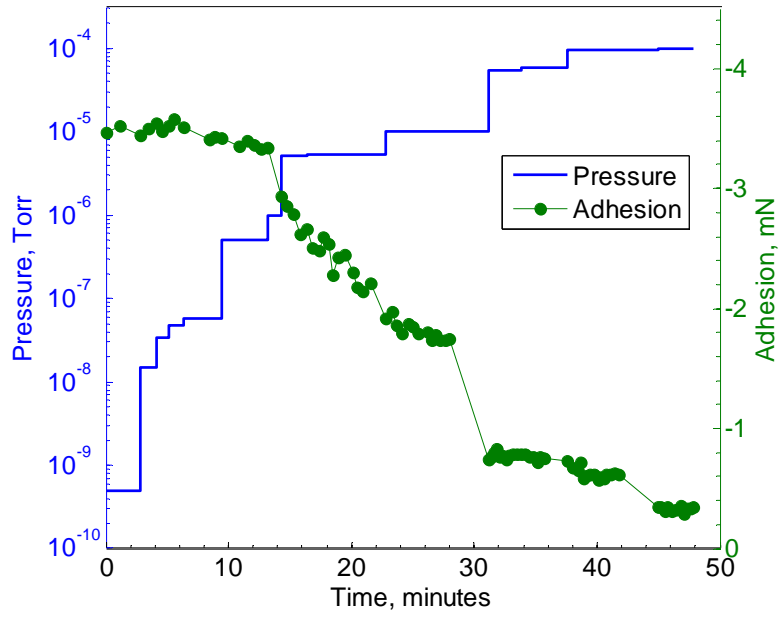

b)

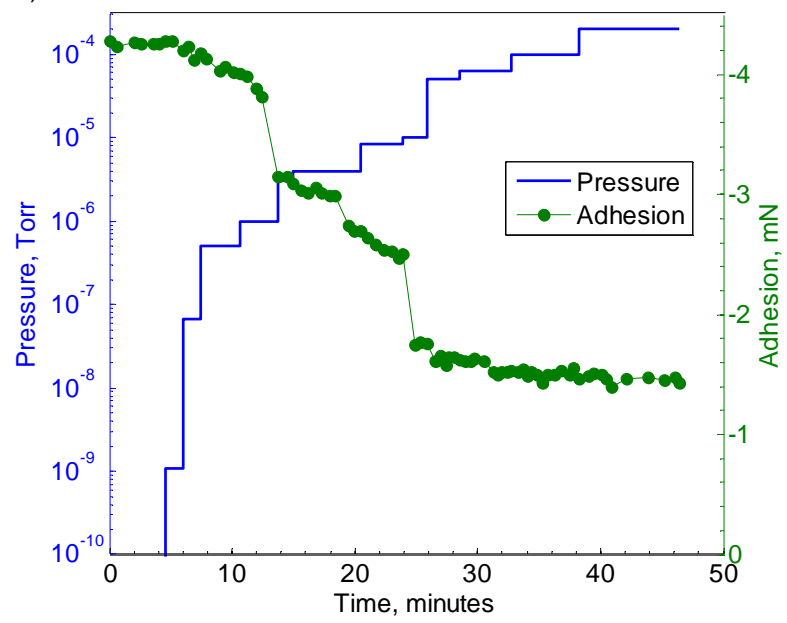

Figure 3.-FEP adhesion as a function of time during an increase of a) Argon pressure and b) air pressure. 


\section{Conclusion}

In a UHV environment, triboelectric charging has been seen in this study to be the single greatest contributor to adhesion, particularly for atomically clean materials with large triboelectric affinities. The electrostatic adhesion was often orders of magnitude greater than Van der Waals forces or adhesion through chemical bonding, except in the case of silicone rubber. In the absence of plasma currents, such as in shadowed craters and sheltered areas of spacecraft triboelectric charging will dominate dust adhesion. In areas exposed to plasma currents or UV photons, triboelectric charging may be compensated (Ref. 16), but surface charge will still remain due to those same currents and photoelectric emission. As we have seen, charge can remain a significant source of adhesion over time scales ranging in hours and days in the absence of the atmospheric discharge effects of gas collisions and absorbed water.

Thus dust mitigation techniques which concentrate on reducing the effects of electrostatic forces will be much more successful over strategies which work to reduce Van der Waals adhesion. Through the use of coatings with a work function matching that of regolith minerals and glasses, or by choosing materials whose triboelectric affinity is similar to that of the dust, triboelectric charging can be limited passively. For example, the implications of triboelectric charging clearly favor the silicate-based paint AZ-93 over uncoated silver-FEP as the choice of thermal control surfaces where dust impingement is expected. In fact, a recent study has shown that work function matching coatings decrease dust adhesion to FEP surfaces in high fidelity tests with lunar simulant particles (Ref. 17). Such areas of heavy dust impingement are likely those where mechanical activities will occur, as a study by Katzan about the sources of lofted dust on the lunar surface revealed (Ref. 11). It should be noted that the dust environment around asteroids is far less known than on the lunar surface. The reduction of triboelectric charging should certainly determine the choices of materials used where intense contact with regolith will occur, such as in mining operations, under any conditions. Active manipulation of the dust and spacecraft surface charge electrostatically, as well as other electrostatic or electrodynamic mitigation techniques (see Ref. 18 for an example) will likely also prove most effective at mitigating dust adhesion.

When testing any mitigation strategies, the vacuum conditions within the test chamber and the monolayer surface contamination of regolith simulant and spacecraft materials are critical and will determine the applicability of any such test to a true airless body environment. Micrometeor impacts and the solar wind will ensure that the dust on the surface of any airless body will be atomically clean, while spacecraft materials will be cleaned by the solar wind within minutes to hours (Ref. 15). Contamination from water and hydrocarbons present on any surface which has been exposed to a terrestrial atmosphere greatly lowers the triboelectric charge transfer, and hence the adhesion. Removal of this contamination layer through a sputtering process or by plasma treatment will be an important step of any high fidelity test. Maintenance of a high to ultrahigh vacuum to prevent later accumulation of surface contaminants will be equally important. Maintenance of a vacuum below $10^{-6}$ torr will also be critical to avoiding discharge of any charged surfaces through collision with background gases. Although no significant drop in the adhesion was observed at $10^{-7}$ torr and below, we recommend that long term (hours) adhesion tests are performed and compared to adhesion loss rates in Reference 13 in order to qualify vacuum chambers for further tests. Ultimately, high fidelity tests and validation of dust adhesion mitigation technology must be made in high or ultrahigh vacuum and include a cleaning step of the regolith simulant and any exposed spacecraft material surfaces. 


\section{References}

1. Review of United States Human Spaceflight Plans Committee, "Seeking a Human Spaceflight Program Worthy of a Great Nation," Augustine, N. R., Chairman, 2009.

2. Gaier, J.R., and Jaworske, D.A., "Lunar Dust on Heat Rejection System Surfaces: Problems and Prospects," NASA TM-2007-214814, 2007.

3. Gaier, J.R., "Regolith Activation on the Lunar Surface and Its Ground Test Simulation," NASA TM2009-215648, 2009.

4. Vander Wal, R. L., "Lunar Dust Chemical, Electrical, and Mechanical Reactivity: Simulation and Characterization," The National Center for Space Exploration Research, NASA CR-2008-215431, Cleveland, OH, Oct. 2008.

5. Gaier, J. R., "The Effects of Lunar Dust on EVA Systems During the Apollo Missions," NASA TM2005-213610/REV1, 2005.

6. O’Brien, B.J., Freden, S.C., and Bates, J.R., "Degradation of Apollo 11 Deployed Instruments Because of Lunar Module Ascent Effects," Journal of Applied Physics, Vol. 41, No. 11, 1970, pp. 4538-4541.

7. Katzan, C.M., Brinker, D.J., and Kress, R., "The Effects of Lunar Dust Accumulation on the Performance of Photovoltaic Arrays," NASA Glenn Research Center, Document ID 19910020924, Brook Park, OH, 1991.

8. Murphy Jr., T.W., et al., "Long-Term Degradation of Optical Devices on the Moon," Icarus, Vol. 208, No. 1, 2010, pp. 31-35.

9. Walton, O.R., “Adhesion of Lunar Dust,” Grainflow Dynamics, Inc., NASA CR-2007-214685, Livermore, CA, Apr. 2007.

10. Sickafoose, A.A., Colwell, J.E., Horányi, M., and Robertson, S., "Photoelectric Charging of Dust Particles in Vacuum," Physical Review Letters, Vol. 84, No. 26, 2000, pp. 6034-6037.

11. Katzan, C.M., and Edwards, J.L., "Lunar Dust Transport and Potential Interactions with Power System Components," NASA, Document ID 19920002733, NASA CR-4404, Brook Park, OH, Nov. 1991.

12. Miyoshi, K., Chikayoshi, M., and Ryuchi, M., "Development of a Torsion Balance for Adhesion Measurements," NASA TM-100799, 1988.

13. Berkebile, S., Street Jr., K.W., and Gaier, J. R., "Adhesion Between Volcanic Glass and Spacecraft Materials in an Airless Body Environment," 3rd Atmospheric and Space Environments Conference, AIAA-2011-3675, 2011. Also NASA TM-2012-217221.

14. Banks, B.A., deGroh, K.K., Rutledge, S.K., and Haytas, C.A., "Consequences of Atomic Oxygen Interaction with Silicone and Silicone Contamination on Surfaces in Low Earth Orbit," NASA TM 1999-209179, presented at the $44^{\text {th }}$ Annual Meeting sponsored by the International Society for Optical Engineering, Denver, Colorado, July 21, 1999.

15. Gaier, J.R., and Berkebile, S., "Implications of Adhesion Studies for Dust Mitigation on Thermal Control Surfaces," AIAA Aerospace Sciences Meeting, AIAA-2012-0875, 2012. Also NASA TM2012-217213.

16. Farrell, W.M., et al., "Concerning the Dissipation of Electrically Charged Objects in the Shadowed Lunar Polar Regions," Geophysical Research Letters, Vol. 35, 2008, pp. L19104.

17. Gaier, J.R., Waters, D.L., Misconin, R.M., Banks, B.A., and Crowder, M., "Evaluation of Surface Modification as a Lunar Dust Mitigation Strategy for Thermal Control Surfaces," $41^{\text {st }}$ International Conference on Environmental Systems, AIAA-2011-5183, 2011. Also NASA TM-2011-217230.

18. Calle, C.I., Buhler, C.R., McFall, J.L., and Snyder, S.J., "Particle Removal by Electrostatic and Dielectrophoretic Forces for Dust Control During Lunar Exploration Missions," Journal of Electrostatics, Vol. 67, No. 2, 2009, pp. 89-92. 



\begin{tabular}{|c|c|c|}
\hline \multicolumn{2}{|c|}{ REPORT DOCUMENTATION PAGE } & $\begin{array}{l}\text { Form Approved } \\
\text { OMB No. 0704-0188 }\end{array}$ \\
\hline \multicolumn{3}{|c|}{ 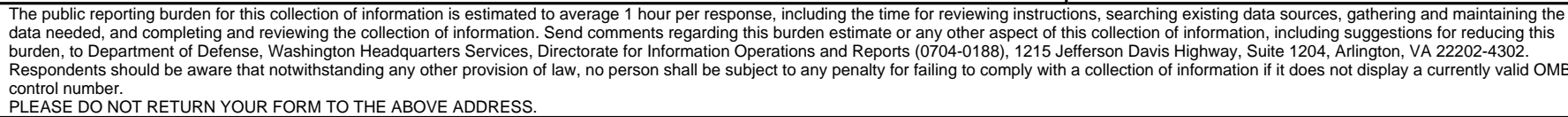 } \\
\hline $\begin{array}{l}\text { 1. REPORT DATE (DD-MM-YYYY) } \\
01-09-2012\end{array}$ & $\begin{array}{l}\text { 2. REPORT TYPE } \\
\text { Technical Memorandum }\end{array}$ & 3. DATES COVERED (From - To) \\
\hline \multicolumn{2}{|c|}{$\begin{array}{l}\text { 4. TITLE AND SUBTITLE } \\
\text { Adhesion in a Vacuum Environment and its Implications for Dust Mitigation Techniques on } \\
\text { Airless Bodies }\end{array}$} & 5c. PROGRAM ELEMENT NUMBER \\
\hline \multicolumn{2}{|c|}{$\begin{array}{l}\text { 6. AUTHOR(S) } \\
\text { Berkebile, Stephen; Gaier, James, R. }\end{array}$} & 5d. PROJECT NUMBER \\
\hline \multicolumn{2}{|c|}{$\begin{array}{l}\text { 7. PERFORMING ORGANIZATION NAME(S) AND ADDRESS(ES) } \\
\text { National Aeronautics and Space Administration } \\
\text { John H. Glenn Research Center at Lewis Field } \\
\text { Cleveland, Ohio 44135-3191 }\end{array}$} & $\begin{array}{l}\text { 8. PERFORMING ORGANIZATION } \\
\text { REPORT NUMBER } \\
\text { E-18434 }\end{array}$ \\
\hline \multirow{2}{*}{\multicolumn{2}{|c|}{$\begin{array}{l}\text { 9. SPONSORING/MONITORING AGENCY NAME(S) AND ADDRESS(ES) } \\
\text { National Aeronautics and Space Administration } \\
\text { Washington, DC 20546-0001 }\end{array}$}} & $\begin{array}{l}\text { 10. SPONSORING/MONITOR'S } \\
\text { ACRONYM(S) } \\
\text { NASA }\end{array}$ \\
\hline & & $\begin{array}{l}\text { 11. SPONSORING/MONITORING } \\
\text { REPORT NUMBER } \\
\text { NASA/TM-2012-217723 }\end{array}$ \\
\hline
\end{tabular}

\section{Unclassified-Unlimited}

Subject Category: 91

Available electronically at http://www.sti.nasa.gov

This publication is available from the NASA Center for AeroSpace Information, 443-757-5802

\section{SUPPLEMENTARY NOTES}

Stephen Berkebile, NASA Glenn Research Center, NASA Postdoctoral Fellow, Oak Ridge Associated Universities.

\section{ABSTRACT}

During the Apollo missions, the adhesion of dust to critical spacecraft systems was a greater problem than anticipated and resulted in functional degradation of thermal control surfaces, spacesuit seals, and other spacecraft components. Notably, Earth-based simulation efforts did not predict the magnitude and effects of dust adhesion in the lunar environment. Forty years later, we understand that the ultrahigh vacuum (UHV) environment, coupled with micrometeorite impacts and constant ion and photon bombardment from the sun result in atomically clean and high surface energy dust particles and spacecraft surfaces. However, both the dominant mechanism of adhesion in airless environments and the conditions for high fidelity simulation tests have still to be determined. The experiments presented in here aim to aid in the development of dust mitigation techniques for airless bodies (e.g., lunar surface, asteroids, moons of outer planets). The approach taken consists of (a) quantifying the adhesion between common polymer and metallic spacecraft materials and a synthetic noritic volcanic glass, as a function of surface cleanliness and of triboelectric charge transfer in a UHV environment, and (b) determining parameters for high fidelity tests through investigation of adhesion dependence on vacuum environment and sample treatment. Adhesion force has been measured between pins of spacecraft materials and a plate of synthetic volcanic glass by determining the pull-off force with a torsion balance. Although no significant adhesion is generally observed directly as a result of high surface energies, the adhesion due to induced electrostatic charge is observed to increase with spacecraft material cleanliness, in some cases by over a factor of 10 . Furthermore, electrostatically-induced adhesion is found to decrease rapidly above pressures of 10-6 torr. It is concluded that high-fidelity tests should be conducted in high to ultrahigh vacuum and include an ionized surface cleaning process.

15. SUBJECT TERMS

Thermal control; Surface properties; Adhesion; Particles; Dust; Minerals; Surface properties; Surface energy

\begin{tabular}{|c|c|c|c|c|c|}
\hline \multicolumn{3}{|c|}{ 16. SECURITY CLASSIFICATION OF: } & $\begin{array}{l}\text { 17. LIMITATION OF } \\
\text { ABSTRACT } \\
\text { UU }\end{array}$ & $\begin{array}{l}\text { 18. NUMBER } \\
\text { OF } \\
\text { PAGES } \\
18\end{array}$ & $\begin{array}{l}\text { 19a. NAME OF RESPONSIBLE PERSON } \\
\text { STI Help Desk (email:help@sti.nasa.gov) } \\
\text { 19b. TELEPHONE NUMBER (include area code) } \\
\text { 443-757-5802 }\end{array}$ \\
\hline
\end{tabular}



